\section{Photosynthetic Characteristics of Individual Strawberry (Fragaria Xananassa Duch.) Leaves under Short-distance Lightning with Blue, Green, and Red LED Lights}

\author{
Yuya Mochizuki ${ }^{1}$ \\ United Graduate School of Agriculture, Tokyo University of Agriculture and \\ Technology, 3-5-8 Saiwaicho, Fuchu, Tokyo 183-8509, Japan
}

Saori Sekiguchi ${ }^{2}$

Graduate School of Agriculture, Tokyo University of Agriculture and Technology, 3-5-8 Saiwaicho, Fuchu, Tokyo 183-8509, Japan

Naomi Horiuchi

Faculty of Agriculture, Tokyo University of Agriculture and Technology, 3-5-8 Saiwaicho, Fuchu, Tokyo 183-8509, Japan

\section{Thanda Aung}

United Graduate School of Agriculture, Tokyo University of Agriculture and Technology, 3-5-8 Saiwaicho, Fuchu, Tokyo 183-8509, Japan

\section{Isao Ogiwara ${ }^{3}$}

United Graduate School of Agriculture, Tokyo University of Agriculture and Technology, 3-5-8 Saiwaicho, Fuchu, Tokyo 183-8509, Japan; Graduate School of Agriculture, Tokyo University of Agriculture and Technology, 3-58 Saiwaicho, Fuchu, Tokyo 183-8509, Japan; and United Graduate School of Agriculture, Tokyo University of Agriculture and Technology, 3-5-8 Saiwaicho, Fuchu, Tokyo 183-8509, Japan

Additional index words. abaxial side of leaves, adaxial side of leaves, leaf intercellular $\mathrm{CO}_{2}$ concentration, stomatal conductance, transpiration rate

\begin{abstract}
To clarify the response of net photosynthetic rate $(\mathrm{Pn})$, stomatal conductance $\left(g_{\mathrm{S}}\right)$, transpiration rate (Tr), and leaf intercellular $\mathrm{CO}_{2}$ concentration (Ci) to irradiance on the adaxial and abaxial sides of mature and young strawberry leaves using blue, green, and red light-emitting diodes (LEDs), irradiation from a short distance was investigated using 'Tochiotome'. Light-photosynthetic response curves of the adaxial side of mature leaves were not different among LED treatments. However, those of the adaxial side of young leaves irradiated with red LEDs were less than those of other LED treatments. Pn of the abaxial side of mature leaves was $42 \%$ to $71 \%$ of the abaxial side. In young leaves, Pn of the abaxial side was $17 \%$ to $68 \%$ of the adaxial side. Moreover, light-transpiration response curves were different with LED treatments. $\mathrm{Ci}$ and $\mathrm{Tr}$ under blue and green LEDs were greater than those under red LEDs. This indicates that blue and green lights affected the stomatal opening. In contrast, red LEDs decreased $\mathrm{Ci}$ more than other LED treatments. In addition, reactions of the adaxial side of young leaves under blue and red LEDs were seen not only in 'Tochiotome', but also in 'Sachinoka' and 'Eran', which indicates that the photosynthetic reactions of blue light and red light are common characteristics of the strawberry. Therefore, red LEDs promoted the photochemical reaction and activated the $\mathrm{CO}_{2}$ fixation system. Based on the results of this study of short-distance lighting with LEDs in strawberry production, irradiance of the abaxial side of leaves by blue or green LEDs might improve more assimilates in young leaves compared with red LEDs to increase strawberry yield.
\end{abstract}

\footnotetext{
Received for publication 10 Sept. 2018. Accepted for publication 12 Dec. 2018.

${ }^{1}$ Current address: College of Agriculture, Ibaraki University, Ami, Inashiki, Ibaraki 300-0393, Japan. ${ }^{2}$ Contributed equally.

${ }^{3}$ Corresponding author. E-mail: ogiwara@cc.tuat. ac.jp.
}

The main cultivation method of strawberry (Fragaria $\times$ ananassa Duch.) in Japan is forcing culture using June-bearing cultivars with flower initiation that is transplanted at the end of September and kept warm from mid October to develop flowers, and then the fruit is harvested from December to the following May. Two kinds of light treatments are carried out in forcing culture; to prevent dormancy with low light intensity and to promote leaf photosynthetic rate with high light intensity. Therefore, day extension and light-break treatments are applied during this cultivation period to prevent strawberry plantlets from dwarfing by low temperatures and a short daylength (Fujishige, 2006). These light treatments are different from the supplemental lightning used to increase photosynthesis. In addition, in this forcing culture, a phenomenon called plant dwarfing, and a decreased yield, occur midwinter at the end of January to mid February. The causes are decreasing assimilation products by low temperatures, short daylength, and low light intensity during midwinter (Shigeno et al., 2001), and growth depression of leaves by preferential assimilate partitioning to fruit (Nishizawa and Hori, 1989).

Based on reports about the effect of supplemental lighting on growth and yield of strawberry (Hidaka et al., 2013; Inada and Matsuno, 1985; Shishido et al., 1995) and photosynthetic characteristics of strawberry leaf blades (Ogiwara et al., 2003), the manner of enhancing leaf photosynthesis by supplemental lightning may be effective in addressing the issues of plant dwarfing and decreased yield during midwinter. However, currently, few strawberry growers in Japan use supplemental lightning for increasing photosynthesis.

Plants adapt to changes in the light environment by controlling their morphology using receptors such as phytochromes, cryptochromes, and phototropin (Ballare and Casal, 2000). Recently, LEDs came to the forefront as a light source in greenhouses because LEDs require less power than existing light sources, they are long-lived, and they are able to emit almost monochromatic light (Massa et al., 2008). Research on the relationship between light wavelength and plant growth are promoted by continuous irradiance of specific wavelength to plantlet with LEDs (Li et al., 2012; Lu et al., 2012; Mizuno et al., 2011). Light requirements are clearly different among plant species (Olle and Virsile, 2013). Plant growth differs based on light quality. Blue light promoted stem elongation of eggplant and sunflower seedlings, and suppressed stem elongation of leaf lettuce (Hirai et al., 2006) and tomato (Li et al., 2017). Green LEDs increased the root dry weight of red leaf lettuce (Johkan et al., 2012), and red LEDs probably prevented strawberry seedlings from excessive stem elongation in a low-temperature treatment in darkness (Fushihara and Mitsui, 1996). In addition, LEDs can irradiate at a close distance from objects because they do not emit energy in the infrared range. Therefore, LEDs are suitable for use to promote plant growth in a controlled environment (Yeh and Chung, 2009). Okamoto and Yoshizawa (1996) reported that diffused reflection by reflective mulch increased the yield of strawberry because light conditions were improved from fruit set to harvest. These results indicate that optimizing a combination of wavelengths and the manner of 
irradiance (such as light intensity and irradiated site) with LEDs could be a strategy to increase yield. In the basic knowledge of photosynthesis, plants absorb red and blue light better than green light, and the characteristic absorption wavelength did not involve temperature and ambient $\mathrm{CO}_{2}$ concentration (McCree, 1971-72). Moreover, Pn of higher plants was the greatest under red, blue, and green, and there were linear relationships between Pn and light intensity (Inada, 1976). Recently, Terashima et al. (2009) reported that a combination of green light and white light was more effective for Pn of sunflower leaves than red light. The effect of photosynthesis is different based on light quality, but there are few reports about the photosynthetic response to different wavelengths in strawberry using LEDs to promote growth. In this study, we clarified the characteristics of the light-photosynthetic response by using LEDs (blue, green, and red) at different wavelengths to promote growth and development of strawberries.

The aim of this study was to establish efficient supplemental lightning based on photosynthetic characteristics of strawberry leaf blades. First, we investigated the photosynthetic characteristics of the adaxial and abaxial sides of mature and young leaves under blue, green, and red LED irradiation for a short time using 'Tochiotome'. Second, the photosynthetic characteristics of the adaxial side of young leaves were compared under red and blue LEDs among three strawberry cultivars: Tochiotome, Sachinoka, and Eran.

\section{Materials and Methods}

Photosynthetic characteristics of strawberry 'Tochiotome' leaves under blue, green, and red LEDs. Three strawberry plants ('Tochiotome') were transplanted to nonwoven fabric pots (diameter, $0.15 \mathrm{~m}$; volume, $2.6 \mathrm{~L}$ ) filled with mixed soil substrate [peatmoss:Kanuma soil: vermiculite $1: 1: 1(\mathrm{v} / \mathrm{v} / \mathrm{v})]$, and caustic lime $(0.4 \mathrm{~g} /$ pot $)$ was added as a basal fertilizer on 23 Sept. 2009. The plants were grown in a greenhouse in Tokyo University of Agriculture and Technology, Tokyo, Japan. On 18 Oct. 2009 , these plants were moved to a phytotron $\left[25^{\circ} \mathrm{C} / 15^{\circ} \mathrm{C}\right.$ (day/night)] to measure

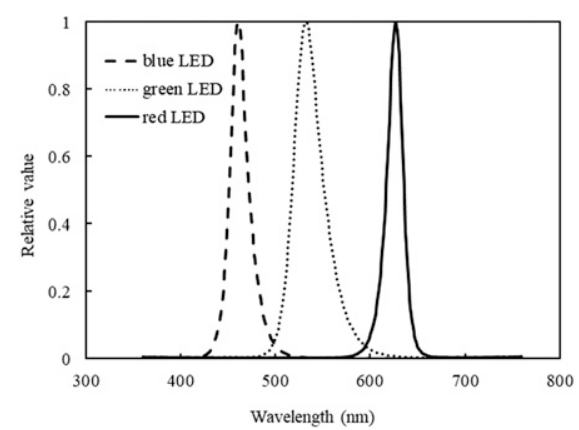

Fig. 1. Spectrum distribution of blue, green, and red light-emitting diodes (LEDs). Relative values are shown for each peak wavelength. photosynthesis. Thereafter, the strawberry plants were moved to a greenhouse. They were supplied with Otsuka A nutrient solution (OAT Agrio Co., Ltd., Tokyo, Japan), electrical conductivity (EC) was adjusted 0.6 before anthesis and $1.2 \mathrm{mS} \cdot \mathrm{cm}^{-1}$ during the harvesting period, $\mathrm{pH}$ ranged from 6.0 to 7.0 , and drainage was $30 \%$ with the fertigation system in the greenhouse and the phytotron. The solution consisted of 4.3 to $8.6 \mathrm{~mm}$ $\mathrm{NO}_{3}^{-}, 2.0$ to $4.0 \mathrm{~mm} \mathrm{~K}{ }^{+}, 1.9$ to $3.8 \mathrm{mM} \mathrm{Ca}^{2+}$, 0.7 to $1.4 \mathrm{mM} \mathrm{Mg}^{2+}, 1.2$ to $2.4 \mathrm{mM} \mathrm{H}_{2} \mathrm{PO}_{4}^{-}$, $0.6-1.2 \mathrm{mg} \cdot \mathrm{L}^{-1} \mathrm{Fe}, 0.35$ to $0.70 \mathrm{mg} \cdot \mathrm{L}^{-1} \mathrm{Mn}$, 0.35 to $0.70 \mathrm{mg} \cdot \mathrm{L}^{-1} \mathrm{~B}, 0.02$ to $0.04 \mathrm{mg} \cdot \mathrm{L}^{-1} \mathrm{Zn}$, 0.006 to $0.012 \mathrm{mg} \cdot \mathrm{L}^{-1} \mathrm{Cu}$, and 0.006 to $0.012 \mathrm{mg} \cdot \mathrm{L}^{-1} \mathrm{Mo}$, and was adjusted to an $\mathrm{EC}$ of $1.0 \mathrm{dS} \cdot \mathrm{m}^{-1}$

Irradiation was applied to the adaxial or abaxial side of mature leaves (fifth or sixth leaf from the youngest leaf of the crown) and young leaves (second leaf) with LEDs. The light sources $(4 \times 11 \mathrm{~cm})$ were blue $(\lambda=460$ $\mathrm{nm})$, green $(\lambda=525 \mathrm{~nm})$, and red $(\lambda=625$ nm) LEDs (OKI Digital Imaging Co., Ltd., Gunma, Japan). The wavelengths were measured by MK 350 (JPR tek, Mial-Li country
350, Taiwan) (Fig. 1). Photosynthetic photon flux density $(P P F D), \mathrm{Pn}, g_{\mathrm{S}}, \mathrm{Tr}$, and $\mathrm{Ci}$ were measured using the LI-6400 Portable Photosynthesis System (LI-COR, Lincoln, NE) on 7, 9, and 13 Dec. 2009 from 0750 to $1730 \mathrm{HR}$. The upper chamber has a $2 \times 3-\mathrm{cm}$ prop film window and the light sources were put on the upper leaf chamber. The measurements were repeated three times under seven different light intensities, increasing gradually from 0 to $600 \mu \mathrm{mol} \cdot \mathrm{m}^{-2} \cdot \mathrm{s}^{-1} P P F D$ with 100 $\mu \mathrm{mol} \cdot \mathrm{m}^{-2} \cdot \mathrm{s}^{-1} P P F D$ intervals measured by a GaAsP photosynthetic active radiation sensor in a leaf chamber under base conditions of a $\mathrm{CO}_{2} 500-\mu \mathrm{mol} \cdot \mathrm{s}^{-1}$ flow and a $\mathrm{CO}_{2}$ concentration of $350 \mu \mathrm{mol} \cdot \mathrm{mol}^{-1}$.

Photosynthetic characteristics of the young leaves of three cultivars under red and blue LEDs. Three plants per each cultivar (Tochiotome, Sachinoka, and Eran) were used. 'Eran' was transplanted to nonwoven fabric pots (diameter, $0.18 \mathrm{~m}$; volume, $3.6 \mathrm{~L}$ ) on 30 Oct. 2009 and was brought to the greenhouse. The fluorescent light was applied from 1700 to $2100 \mathrm{HR}$ and from 0100 to $0200 \mathrm{HR}$ for a light break, and the inside
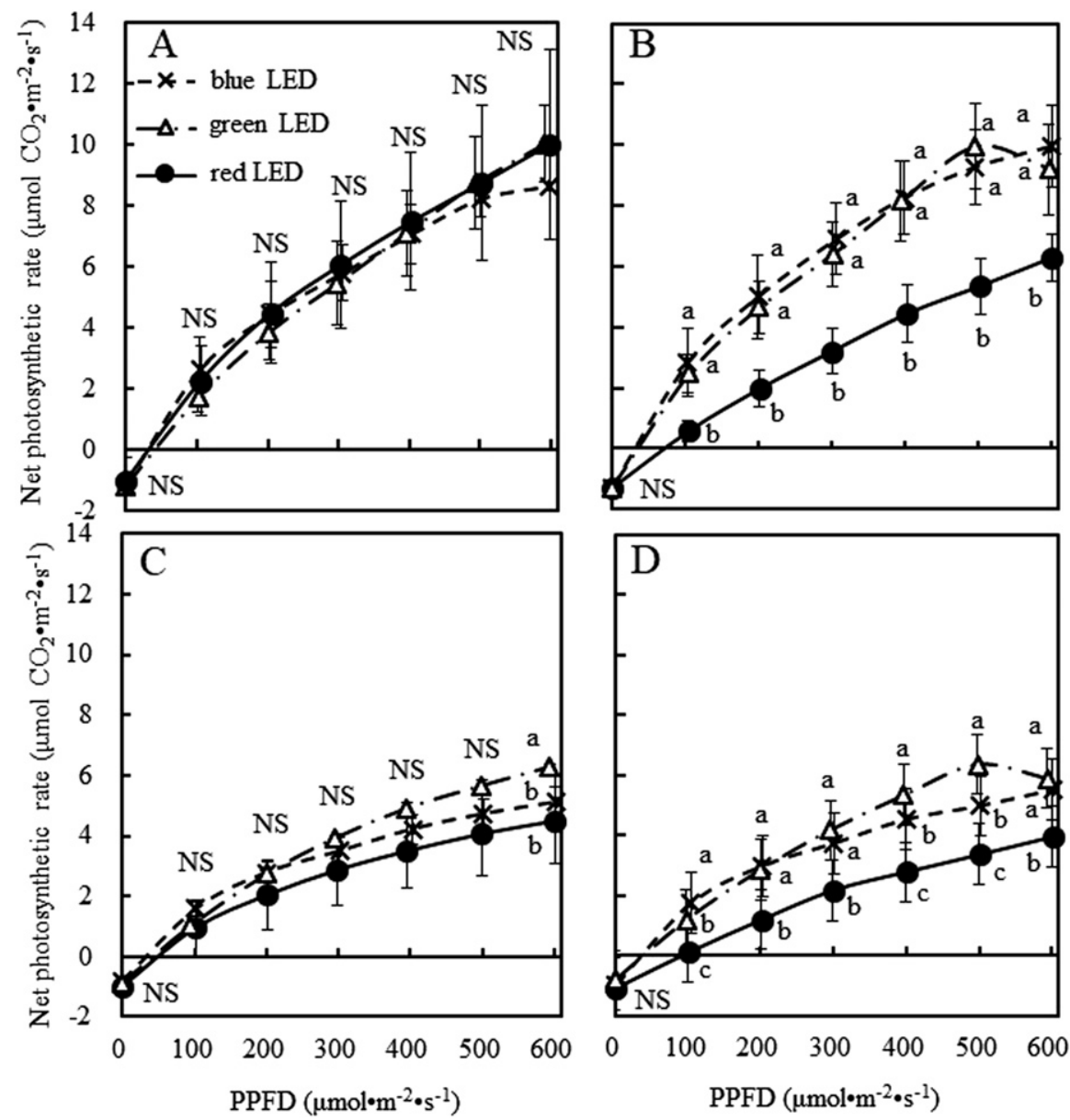

Fig. 2. Responses of net photosynthetic rates to irradiance for strawberry leaves - adaxial side of (A) mature leaves and $(\mathbf{B})$ young leaves, abaxial side of $(\mathbf{C})$ mature leaves and (D) young leaves - by blue, green, and red light-emitting diodes (LEDs). The mature leaves are the fifth or sixth leaf count from an expanding leaf and the young leaves are the second leaf. Error bars indicate $\operatorname{SD}(n=3)$. Different letters indicate significant differences and NS means nonsignificance among the light qualities at each photosynthetic photon flux density $(P P F D)$ by Fisher's protected least significant difference test $(P=0.05)$.

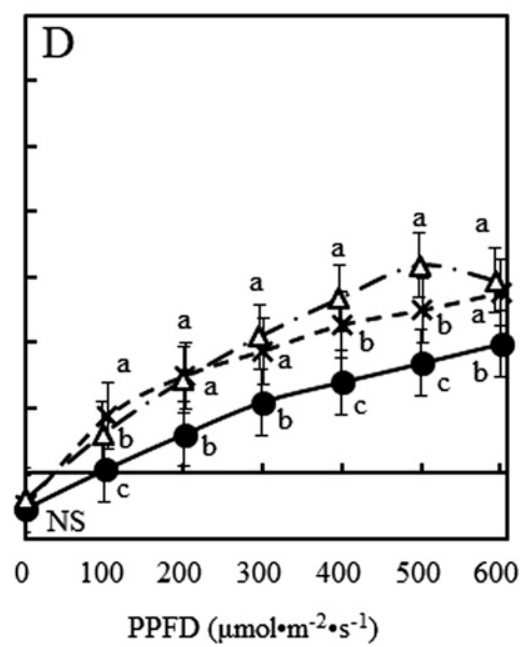

HortScience Vol. 54(3) March 2019 
temperature was maintained at more than $5{ }^{\circ} \mathrm{C}$ using plastic curtains and a heater. 'Tochiotome' and 'Sachinoka' were transplanted to nonwoven fabric pots (diameter, $0.18 \mathrm{~m}$; volume, $3.6 \mathrm{~L}$ ) on 16 Apr. 2010. These plants were placed in the phytotron on 7 May 2010. Cultivation management of the plants was the same as described earlier.

The adaxial sides of young leaves were irradiated with red and blue LEDs, and photosynthetic characteristics were investigated on 9, 10, and 25 May 2010, and 1, 6, and 7 June 2010. The conditions of measurement were the same as described earlier.

\section{Results}

Photosynthetic characteristics of strawberry 'Tochiotome' leaves under blue, green, and red LEDs. By irradiating the adaxial and abaxial sides of mature and young leaves of 'Tochiotome' with blue, green, and red LEDs for a short time (Fig. 2), the lightphotosynthetic response curves of the adaxial side of mature leaves showed that the photosynthetic rate increased with increasing $P P F D$, but there were no differences among light qualities (Fig. 2A). Although lightphotosynthetic response curves of blue and green LEDs on the adaxial side of young leaves showed the same tendencies, the Pn of red LEDs tended to be less than that of blue and green LEDs (Fig. 2B). The Pn of the abaxial side of mature leaves was $42 \%$ to $71 \%$ less than that of the adaxial side when the average Pn of the abaxial side was divided by the value of the adaxial side for each quality and each $P P F D$ (except $\left.0 \mu \mathrm{mol} \cdot \mathrm{m}^{-2} \cdot \mathrm{s}^{-1} P P F D\right)$ (Fig. $2 \mathrm{~A}$ and C). For the young leaves, the Pn of the abaxial side was $17 \%$ to $68 \%$ less than that of the adaxial side (Fig. 2B and D).

By irradiating the adaxial side of mature leaves with LEDs, $g_{\mathrm{S}}, \mathrm{Tr}$, and $\mathrm{Ci}$ were different among light qualities (Fig. 3). Although $g_{\mathrm{S}}$ and Tr of the adaxial side of mature leaves were not significantly different among light qualities (Fig. 3A and C). Those values for the adaxial side of young leaves under blue and green LEDs were greater than those of red LEDs at $300 \mu \mathrm{mol} \cdot \mathrm{m}^{-2} \cdot \mathrm{s}^{-1}$ PPFD (Fig. 3B and D). The $g_{\mathrm{S}}$ and $\mathrm{Tr}$ of mature leave under red LEDs increased a bit (Fig. 3A and $\mathrm{C}$ ); however, these values did not increase in young leaves (Fig. 3B and D). With regard to $\mathrm{Ci}$ for mature leaves, there was the same tendency toward decreasing values under all LEDs (Fig. 3E). The values under blue and green LEDs increased slightly at 300 $\mu \mathrm{mol} \cdot \mathrm{m}^{-2} \cdot \mathrm{s}^{-1} P P F D$, whereas the red LED values did not (Fig. 3E). In young leaves, $\mathrm{Ci}$ under blue and green LEDs showed the same tendency as mature leaves, but the values under red LEDs decreased gradually with increasing PPFD (Fig. 3F). When the light intensity was less than $300 \mu \mathrm{mol} \cdot \mathrm{m}^{-2} \cdot \mathrm{s}^{-1} P P F D$, $\mathrm{Ci}$ under red LEDs was greater than the values under blue and green LEDs (Fig. 3F).

In addition, the $g_{\mathrm{S}}$ and $\mathrm{Tr}$ of the abaxial sides of mature leaves under blue and green LEDs were significantly greater than those under red LEDs (Fig. 4A and C). Ci of the abaxial sides of mature leaves (Fig. 4E) showed the same tendency as the adaxial sides (Fig. 3E). In young leaves, $g_{\mathrm{S}}$, Tr, and $\mathrm{Ci}$ of the abaxial sides (Fig. 4B, D, and F) showed the same tendency as the adaxial sides (Fig. 3B, D, and F).

Leaf temperature and leaf-to-air vapor pressure are presented in Table 1. The leaf temperature of the adaxial side of young leaves under red LEDs was the least in those of other treatments. The leaf temperature of the abaxial side of young leaves under green LEDs was greatest in those of other treatments. The leaf-to-air vapor pressure deficit had the same tendency as leaf temperature.

Photosynthetic characteristics of three cultivars of young leaf blades under red and blue LEDs. Further investigation was carried out to prove the photosynthetic characteristics of young leaves under red LEDs using three strawberry cultivars (Figs. 5 and 6). By irradiating the adaxial side of young leaves of 'Tochiotome', 'Sachinoka', and 'Eran' with red and blue LEDs, the Pn under both LEDs increased with increasing $P P F D$, but the values under red LEDs were less than those values under blue LEDs in all cultivars (Fig. 5). Furthermore, $g_{\mathrm{S}}$ and $\mathrm{Tr}$ of all cultivars under blue LEDs increased with increasing PPFD, whereas those values under red LEDs were nearly the same at all PPFDs (Fig. 6A-F). With regard to $\mathrm{Ci}$, the values under red LEDs decreased gradually with increasing $P P F D$ compared with blue LEDs, except for 'Eran' at $100 \mu \mathrm{mol} \cdot \mathrm{m}^{-2} \cdot \mathrm{s}^{-1}$ PPFD (Fig. 6G-I).
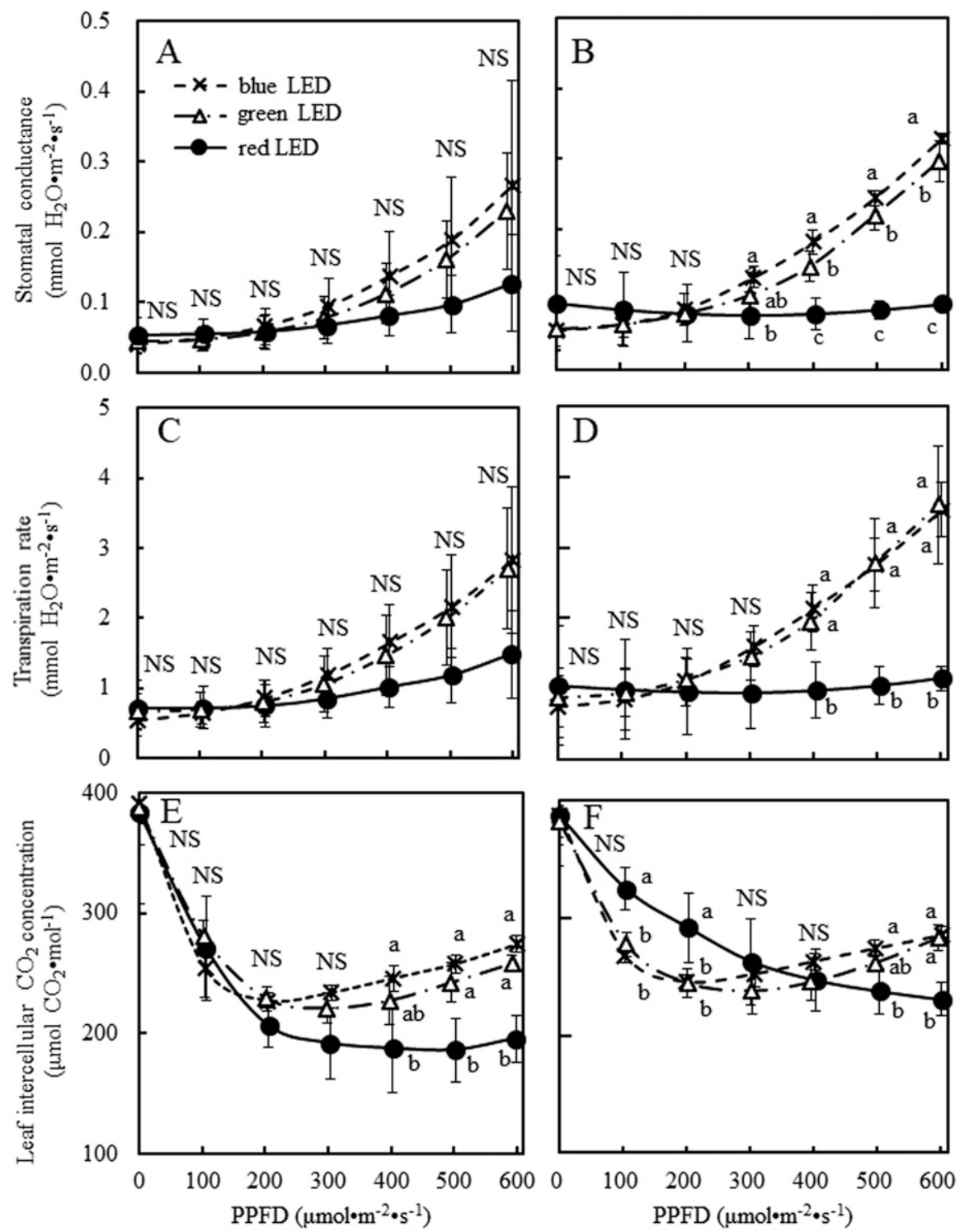

Fig. 3. Responses of stomatal conductance, leaf intercellular $\mathrm{CO}_{2}$ concentrations, and transpiration rates to irradiance for the adaxial side of $(\mathbf{A}, \mathbf{C}, \mathbf{E})$ mature strawberry leaves and $(\mathbf{B}, \mathbf{D}, \mathbf{F})$ young strawberry leaves by blue, green, and red light-emitting diodes (LEDs). The mature leaves are the fifth or sixth leaf count from an expanding leaf and the young leaves are the second leaf. Error bars indicate $\operatorname{SD}(n=3)$. Different letters indicate significant differences and Ns means nonsignificance among the light qualities at each photosynthetic photon flux density $(P P F D)$ by Fisher's protected least significant difference test $(P=0.05)$. 

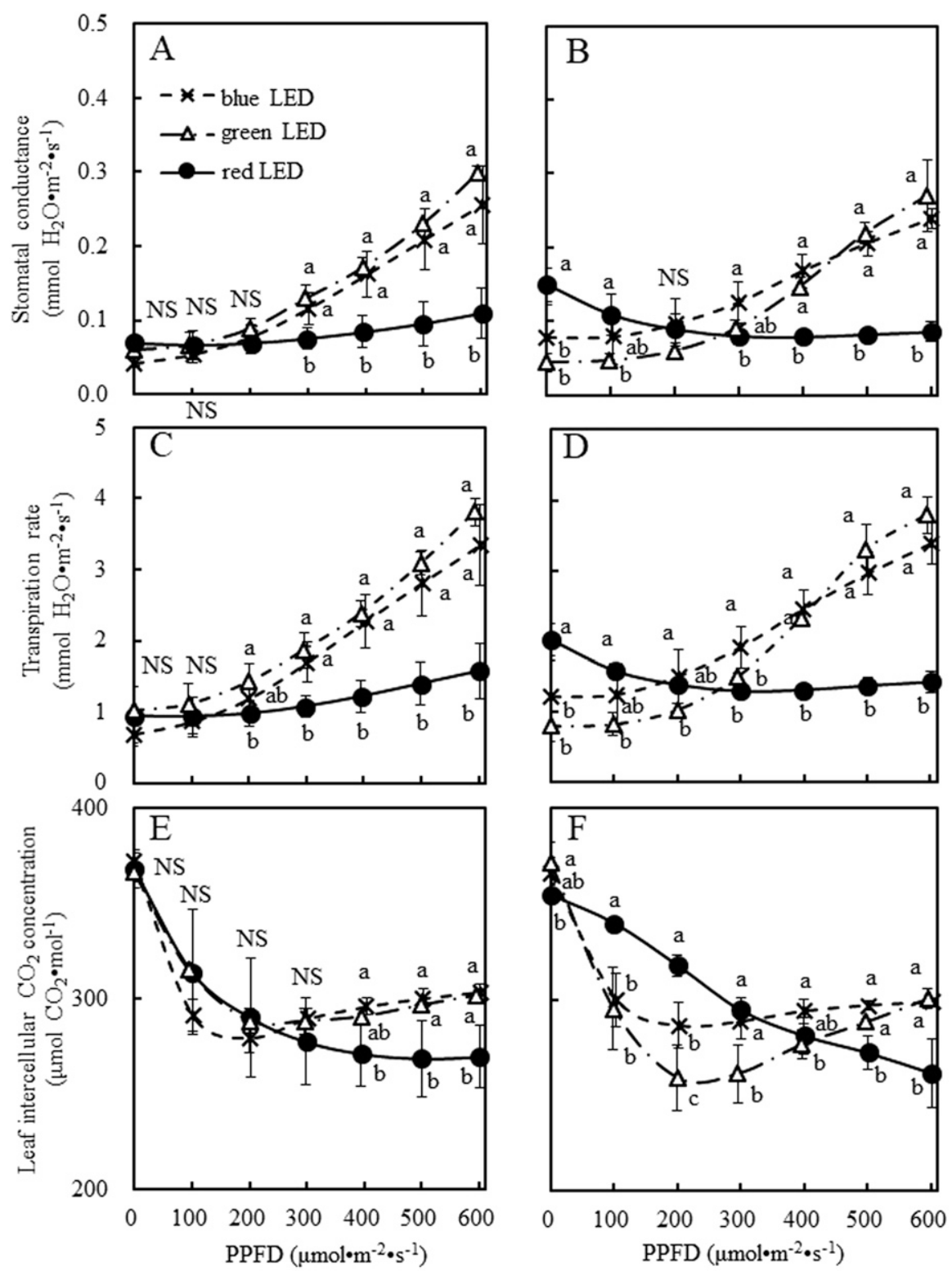

Fig. 4. Responses of stomatal conductance, leaf intercellular $\mathrm{CO}_{2}$ concentrations and transpiration rates to irradiance for abaxial side of $(\mathbf{A}, \mathbf{C}, \mathbf{E})$ mature strawberry leaves and $(\mathbf{B}, \mathbf{D}, \mathbf{F})$ younger strawberry leaves by blue, green, and red light-emitting diodes (LEDs). The mature leaves are the fifth or sixth leaf count from an expanding leaf and the young leaves are the second leaf. Error bars indicate SD $(n=3)$. Different letters indicate significant differences and Ns means nonsignificance among the light qualities at each photosynthetic photon flux density $(P P F D)$ by Fisher's protected least significant difference test $(P=0.05)$.

Table 1. Effects of different light-emitting diode treatments on leaf temperature and leaf-to-air vapor pressure deficits in mature and young strawberry leaves.

\begin{tabular}{lllllllll}
\hline & & \multicolumn{3}{c}{ Leaf temp $\left({ }^{\circ} \mathrm{C}\right)$} & & \multicolumn{3}{c}{ Leaf-to-air vapor pressure deficits $(\mathrm{kPa})$} \\
\cline { 3 - 5 } Leaf stage & Side of leaves & Blue & Green & Red & & Blue & Green & Red \\
\hline Mature & Adaxial side & $30.8 \mathrm{abc}^{2}$ & $30.8 \mathrm{abc}$ & $30.3 \mathrm{~cd}$ & & $1.33 \mathrm{efg}$ & $1.39 \mathrm{def}$ & $1.31 \mathrm{fg}$ \\
Young & Adaxial side & $30.5 \mathrm{abc}$ & $31.0 \mathrm{ab}$ & $29.5 \mathrm{e}$ & & $1.30 \mathrm{fg}$ & $1.44 \mathrm{cde}$ & $1.22 \mathrm{~g}$ \\
Mature & Abaxial side & $30.5 \mathrm{abc}$ & $30.7 \mathrm{abc}$ & $29.8 \mathrm{de}$ & & $1.54 \mathrm{abc}$ & $1.57 \mathrm{ab}$ & $1.49 \mathrm{bcd}$ \\
Young & Abaxial side & $30.5 \mathrm{ab}$ & $31.1 \mathrm{a}$ & $30.3 \mathrm{c}$ & & $1.52 \mathrm{abc}$ & $1.63 \mathrm{a}$ & $1.62 \mathrm{a}$ \\
\hline
\end{tabular}

${ }^{\mathrm{z}}$ Different letters indicate significant differences at $P<0.05$ by analysis of variance according to Tukey's multiple comparison test.

\section{Discussion}

When the adaxial sides of mature strawberry leaves were irradiated under blue, green, and red LEDs in this experiment, the light-photosynthetic response curves were not

HortScience Vol. 54(3) March 2019 different among light qualities, although it was expected that Pn under red light would be the greatest among all treatments (Fig. 2A). Based on these findings, we confirmed that blue, green, and red light are used in photosynthesis
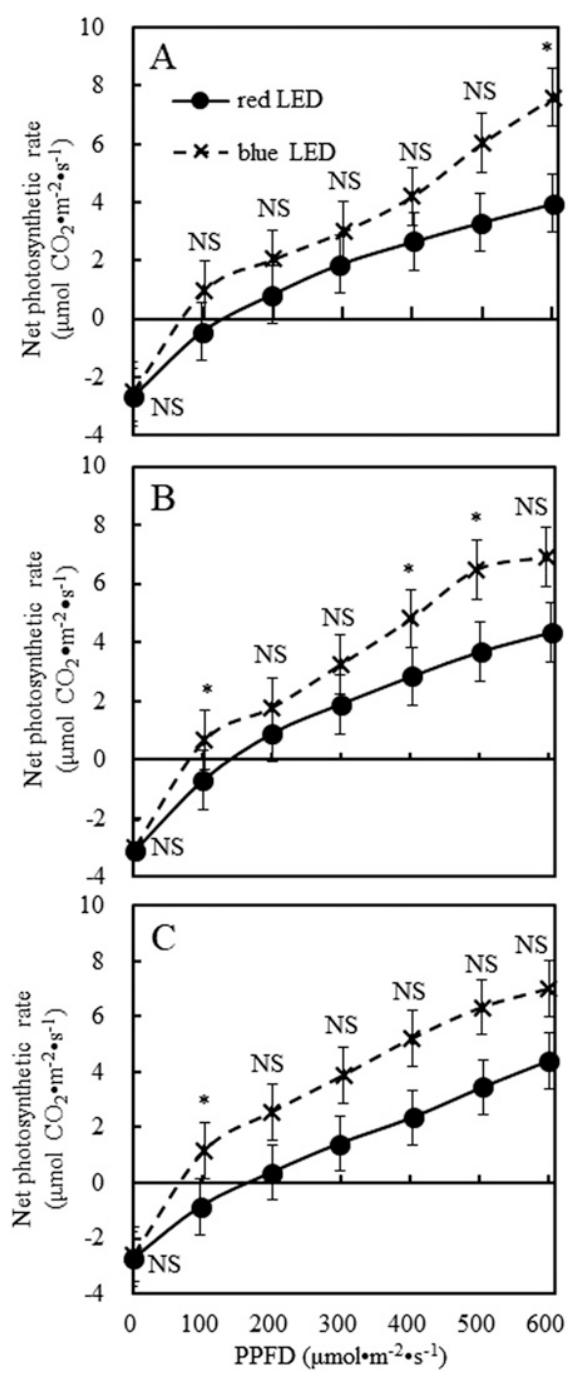

Fig. 5. Comparison of net photosynthetic rates to be irradiated on the adaxial side of young strawberry leaves by blue and red light-emitting diodes (LEDs) on (A) 'Tochiotome', (B) 'Sachinoka', and (C) and 'Eran'. The young leaves are the second leaf count from an expanding leaf. Error bars indicate SD $(\mathrm{n}=3)$. NS and * mean nonsignificance and significance $(P=0.05)$, respectively, between the light qualities at each photosynthetic photon flux density (PPFD) by $t$ test.

of strawberry leaves. The incoming light of a leaf is absorbed into the pigment molecule of light harvesting complex on the thylakoid membrane and then the electron of special pair of chlorophyll a in the photosynthetic reaction center complex protein become energized and photochemical reaction starts (Raven et al., 2005). Blue light and red light are absorbed well into photosynthetic pigments while green light is hard to be absorbed into them (Raven et al., 2005). According to Terashima et al. (2009), green light was also well absorbed and was used in photosynthesis because green light reflected many times in a leaf through the chloroplast and this internal reflection was related to the differentiation and development of the palisade layer and 


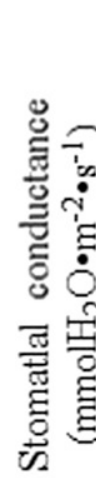

0.2
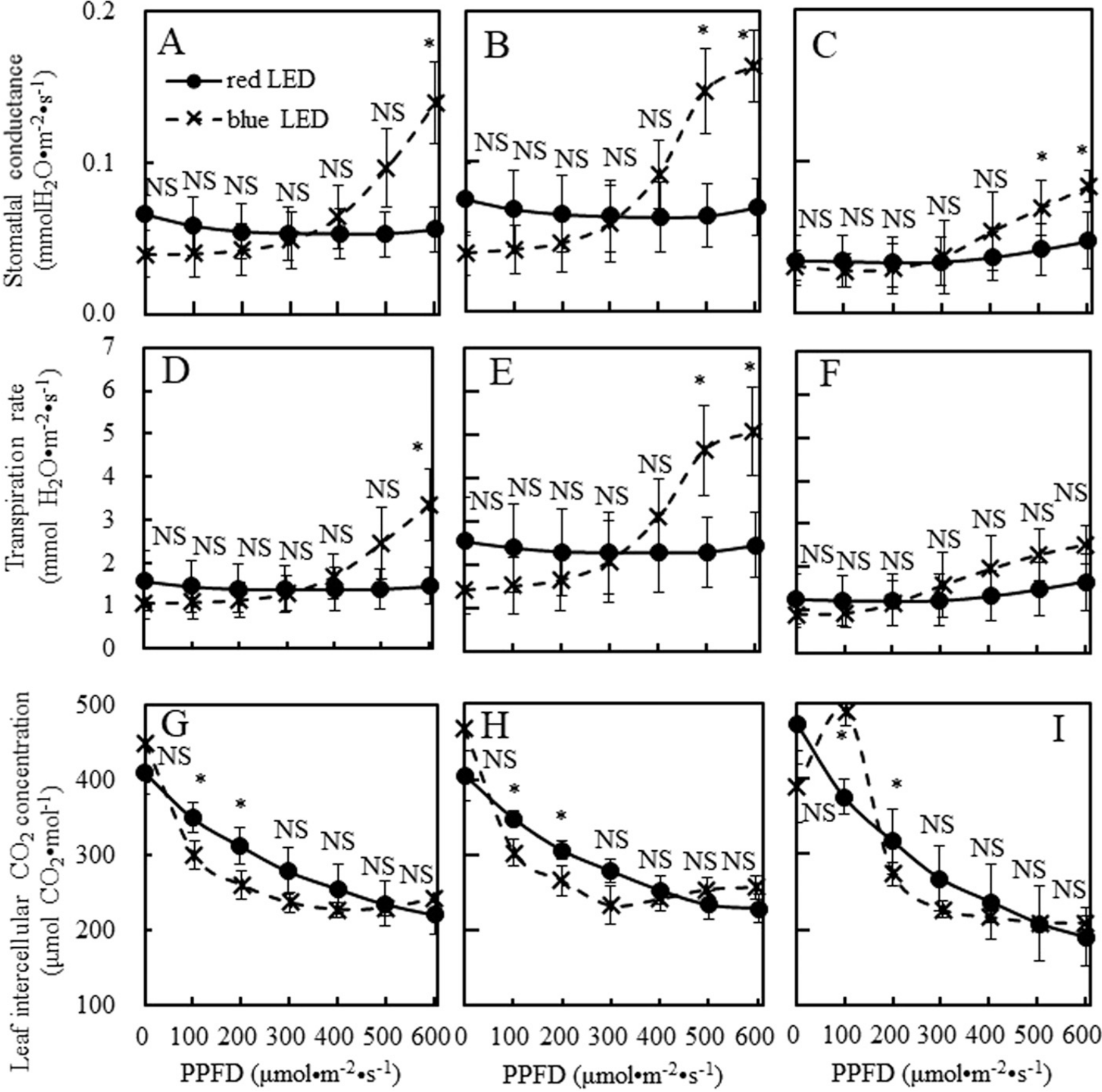

Fig. 6. Comparisons of stomatal conductance, leaf intercellular $\mathrm{CO}_{2}$ concentrations and transpiration rates to be irradiated on the adaxial side of young strawberry leaves by blue and red light-emitting diodes (LEDs) on $(\mathbf{A}, \mathbf{D}, \mathbf{G})$ 'Tochiotome', $(\mathbf{B}, \mathbf{E}, \mathbf{H})$ 'Sachinoka', and $(\mathbf{C}, \mathbf{F}, \mathbf{I})$ 'Eran'. The young leaves are the second leaf count from an expanding leaf. Error bars indicate SD $(\mathrm{n}=3)$. NS and * mean nonsignificance and significance $(P=0.05)$, respectively, between the light qualities at each photosynthetic photon flux density $(P P F D)$ by $t$ test.

the spongy parenchyma. Therefore, our investigation revealed that strawberry leaves might use green light efficiently because the Pn of all treatments under green LEDs was almost same as the values under blue LEDs.

However, the $g_{\mathrm{S}}, \mathrm{Tr}$, and $\mathrm{Ci}$ (Figs. 3 and 4 ) showed different characteristics among light qualities. The $g_{\mathrm{S}}$ and $\mathrm{Tr}$ under blue and green LEDs were greater than those under red LED (Figs. 3B, D, and 4A-D) whereas $\mathrm{Ci}$ under red LEDs was less than the values under blue and green LEDs when the light intensity was more than $300 \mu \mathrm{mol} \cdot \mathrm{m}^{-2} \cdot \mathrm{s}^{-1} P P F D$ (Figs. 3E and 4E).

Sharkey and Raschke (1981) reported that the $g_{\mathrm{S}}$ of Xanthium strumarium L. leaves under blue light were 10 times more effective than under red light, and stomata responded only slightly to green light. Wang et al. (2008) reported that sunflower leaves were induced to open the abaxial stomata via green monochromatic light, but not the adaxial stomata. In our study, $g_{\mathrm{S}}$ of strawberry leaves under green light increased with increasing $P P F D$ regardless of the irradiated site.
According to the results of our study, increased Pn under a high $P P F D$ with blue and green lights might not only be the result of increased $P P F D$, but also the result of opening the stomata with those lights to take up more $\mathrm{CO}_{2}$ easily into the leaf. Increased $\mathrm{Pn}$ under high $P P F D$ with red light might be the result of absorption of the light into chlorophyll a in the photosynthetic reaction center complex protein, the peak of the absorption wavelength is $680 \mathrm{~nm}$, and then photochemical reaction might be promoted, and the carbon fixation might be activated. Reactions 
in the adaxial side of young leaves under blue and red LEDs were seen in not only 'Tochiotome', but also in 'Sachinoka' and 'Eran' (Fig. 6). However, these differences in mechanism of action to photosynthesis were not seen under weak light of less than 300 $\mu \mathrm{mol} \cdot \mathrm{m}^{-2} \cdot \mathrm{s}^{-1}$ PPFD.

With regard to irradiating the adaxial side of young strawberry leaves, the Pn of red LEDs was less than the values found using blue and green LEDs (Fig. 2B) compared with the adaxial side of mature leaves (Fig. 2A). Moreover, $\mathrm{Ci}$ of the adaxial side of young leaves under red LEDs decreased gradually (Fig. 3F) compared with the values of the adaxial side of mature leaves (Fig. 3E). Hirasawa et al. (1989) reported that Pn is decreased by decreasing photosynthetic activity if the Ci response curve is increased. In our study, the photosynthetic activity of young leaves under red LEDs might be less than that of mature leaves because the reduced $\mathrm{Pn}$ and the changes in the Ci response curves in young leaves compared with mature leaves were shown. A similar pattern in Ci was seen in 'Sachinoka' and 'Eran' in our study (Fig. 6H and I).

The Pn of the abaxial side of mature leaves was $42 \%$ to $71 \%$ less than that of the adaxial side for each quality and each PPFD (except $0 \mu \mathrm{mol} \cdot \mathrm{m}^{-2} \cdot \mathrm{s}^{-1} P P F D$ ) (Fig. $2 \mathrm{~A}$ and C). In young leaves, the Pn of the abaxial side was $17 \%$ to $68 \%$ less than that of the adaxial side (Fig. 2B and D). It was thought that the ratio of the light reflection was greater on the abaxial side of leaves with spongy parenchyma that had the small density of stomata. Ko and Yabuki (1974) reported that in some crops in which both sides of a leaf were irradiated by monochromatic light, the amount of assimilation increased more than in crops that irradiated the adaxial side only with the same light intensity. It is assumed that the supplemental light from the abaxial side of the leaves might increase Pn efficiency when exposed to sunlight or artificial light that irradiates the adaxial side of leaves. Moreover, with regard to short-distance lighting with LEDs in strawberry production, irradiance on the abaxial side of leaves by blue or green LEDs might improve more assimilates in young leaves because these lights help stomata opening, compared with red LEDs to increase strawberry yield.

Yanagi and Okamoto (1996) reported photosynthetic characteristics using a combination of wavelengths. They found that Pn of strawberry leaf blades decreased with decreasing light intensity of blue LEDs. In contrast, Tr did not change when the leaves were irradiated with blue LEDs with changing light intensities (i.e., 0, 17, 40, and 60 $\left.\mu \mathrm{mol} \cdot \mathrm{m}^{-2} \cdot \mathrm{s}^{-1} P P F D\right)$ and with red LEDs at $160 \mu \mathrm{mol} \cdot \mathrm{m}^{-2} \cdot \mathrm{s}^{-1} P P F D$. Their results indicate that weak blue light combined with red light did not affect Tr.

Lin et al. (2014) studied the growth, development, nutritional quality, and edible quality of lettuce grown hydroponically under red and blue LEDs with (RBW) and without (RB) supplemental white LED lighting at the same light intensity. Shoot and root fresh and dry weights as well the crispness, sweetness, and shape of the plants treated with RBW were greater than those of plants treated with $\mathrm{RB}$. The soluble sugar and nitrate contents in plants grown using the RBW treatment were significantly greater and less, respectively, compared with those with the RB treatment. However, the chlorophyll, carotenoid, and soluble protein contents of lettuce leaves showed no significant differences among treatments.

Terashima et al. (2009) reported that a combination of $150 \mu \mathrm{mol} \cdot \mathrm{m}^{-2} \cdot \mathrm{s}^{-1} P P F D$ green light and $200 \mu \mathrm{mol} \cdot \mathrm{m}^{-2} \cdot \mathrm{s}^{-1} P P F D$ white light was more effective for Pn than $150 \mu \mathrm{mol} \cdot \mathrm{m}^{-2} \cdot \mathrm{s}^{-1} P P F D$ red light. They discovered that the effects on Pn were different depending on the combination of the light quality with white light. These reports indicate the possibility that effects on Pn depend on a combination of light quality and light intensity.

According to Hirai et al. (2006), who investigated the effect of light quality on the growth and the morphology of plants using LEDs as a monochromatic light source, the effect of light quality was different among plant species and developmental stages. Suzuki et al. (2012) reported that Pn of young tea plants grown under blue LEDs and white LEDs of $100 \mu \mathrm{mol} \cdot \mathrm{m}^{-2} \cdot \mathrm{s}^{-1} P P F D$ for $15 \mathrm{~d}$ was greater than that for plants grown under red LEDs, although there were no differences in young leave growth with differing light quality. Masuda et al. (2004) reported that continuous lighting with blue light changed the leaf color to dark green, but Pn was not significantly different between red light and blue light. However, growth of plants under blue light was poor. These reports indicate that long-term supplemental lighting affects plant photosynthesis and morphogenesis.

\section{Literature Cited}

Ballare, C.L. and J.J. Casal. 2000. Light signals perceived by and weed plants. Field Crops Res. 67:149-160.

Fujishige, N. 2006. Strawberry, p. 115-120. In: JSHS (eds.). Horticulture in Japan 2006. Shoukadoh Publication, Kyoto, Japan.

Fushihara, H. and H. Mitsui. 1996. Effects of wavelength and intensity of light emitting diodes petiole elongation, size of leaf blade and leaf color in strawberry under dark-cooling treatment. Engeigaku Kenkyuu 65(Suppl. 1): 330-331. (In Japanese).

Hidaka, K., K. Dan, H. Imamura, Y. Miyoshi, T. Takayama, K. Sameshima, M. Kitano, and M. Okimura. 2013. Effect of supplemental lighting from different light sources on growth and yield of strawberry. Environ. Control Biol. $51: 41-47$

Hirai, T., W. Amaki, and H. Watanabe. 2006. Effects of monochromatic light irradiation by LED on the internodal stem elongation of seedlings in eggplant, leaf lettuce and sunflower. J. SHITA. 18:160-166. (In Japanese with English abstract).

Hirasawa, T., Y. Iida, and K. Ishihara. 1989 Dominant factors in reduction of photosynthetic rate affected by air humidity and leaf water potential in rice plants. Jpn. J. Crop. Sci.
58:383-389. (In Japanese with English abstract).

Inada, K. 1976. Action spectra for photosynthesis in higher plants. Plant Cell Physiol. 17:355-365.

Inada, K. and A. Matsuno. 1985. Interactions among spectral components of radiation in the growth responses of rice, tomato and strawberry. Jpn. J. Crop. Sci. 54:403-412.

Johkan, M., K. Shoji, F. Goto, S. Hahida, and T. Yoshihara. 2012. Effect of green light wavelength and intensity on photomorphogenesis and photosynthesis in Lactuca sativa. Environ. Exp. Bot. 75:128-133.

Ko, B. and K. Yabuki. 1974. The dependence of relation between light quality and photosynthesis on optical anatomical characteristics of leaves (1). J. Agr. Meteorol. 29:229-237. (In Japanese with English summary).

Li, H., C. Tang, Z. Xu, X. Liu, and X. Han. 2012. Effects of different light sources on the growth of non-heading Chinese cabbage (Brassica campestris L.). J. Agr. Sci. 4:262-273.

Li, Y., G. Xin, M. Wei, Q. Shi, F. Yang, and X. Wang. 2017. Carbohydrate accumulation and sucrose metabolism responses in tomato seedling leaves when subjected to different light qualities. Scientia Hort. 225:490-497.

Lin, K., M. Huang, W. Huang, M. Hsu, Z. Yang, and C. Yang. 2014. The effects of red, blue, and white light-emitting diodes on the growth, development and edible quality of hydroponically grown lettuce (Lactuca sativa $\mathrm{L}$. var. capitate). Scientia Hort. 150:86-91.

Lu, N., T. Maruo, M. Johkan, M. Honjo, S. Tsukagoshi, Y. Ito, T. Ichimura, and Y. Shinohara. 2012. Effects of supplemental lighting with light-emitting diodes (LEDs) on tomato yield and quality of single-truss tomato plants grown at high planting density. Environ. Control Biol. 50:63-74.

Massa, G.D., H.H. Kim, R.M. Wheeler, and C.A Michell. 2008. Plant productivity in response to LED lighting. HortScience 43:1951-1956.

Masuda, M., H. Nakachi, K. Murakami, and Y. Yoshida. 2004. Growth and dry matter production of sweet pepper under continuous lighting of fluorescent lamps different light qualities. J. SHITA. 16:131-136. (In Japanese with English summary).

McCree, K.J. 1971-72. The action spectrum, absorptance and quantum yield of photosynthesis in crop plants. Agr. Meteorol. 9:191-216.

Mizuno, T., W. Amaki, and H. Watanabe. 2011. Effects of monochromatic light irradiation by LED on the growth and anthocyanin contents in leaves of cabbage seedlings. Acta Hort. 907:179-184.

Nishizawa, T. and Y. Hori. 1989. Photosynthesis and translocation of recently assimilated carbon in vegetative and dormant stages of strawberry plants. J. Jpn. Soc. Hort. Sci. 57:633-641. (In Japanese with English summary).

Ogiwara, I., M. Funayama, and T. Hirasawa. 2003. Photosynthetic characteristics of 'Sachinoka' and 'Tochiotome' strawberries during fruit maturation. Hort. Res. 72(Suppl. 2):161. (In Japanese).

Okamoto, M., and K. Yoshizawa. 1996. Effect of reflective film mulching on yield and quality of strawberry in NFT hydroponics. Kinki Chugoku Agr. Res. 92:44-49. (In Japanese).

Olle, M., and A. Virsile. 2013. The effects of lightemitting diode lighting on green house plant growth and quality. Agr. Food Sci. 22:223-234.

Raven, P.H., G.B. Johnson, J.B. Losos, and S.R Singer. 2005. Biology. 7th ed. McGraw-Hill, New York, NY.

Sharkey, T.D. and K. Raschke. 1981. Effect of light quality on stomatal opening in leaves of Xanthium strumarium L. Plant Physiol. 68:1170-1174. 
Shigeno, T., H. Tochigi, Y. Oohashi, and Y. Inaba. 2001. Effect of electric illumination, carbon dioxide supplementation and underground heating on the growth and yield of strawberry 'Tochiotome' in forcing culture. Bull. Tochigi Agr. Exp. Stn. 50:39-49. (In Japanese with English summary).

Shishido, Y., T. Nishizawa, H. Kumakura, and H. Hamamoto. 1995. Studies on photomorphogenesis in vegetables: 1. Effects of red light irradiation on petiole elongation of strawberry during low temperature treatment in the continuous dark. Hort. Res. 64(Suppl. 1):348-349. (In Japanese).
Suzuki, T., M. Nakamura, N. Kataoka, T. Ikka, and A. Morita. 2012. Effects of low light quality on photosynthesis and nitrogen assimilation of young tea plants. J. SHITA. 24:16-24. (In Japanese with English abstract).

Terashima, I., T. Fujita, T. Inoue, W.S. Chow, and R. Oguchi. 2009. Green light drives leaf photosynthesis more efficiently than red light in strong white light: Revisiting the enigmatic question of why leaves are green. Plant Cell Physiol. 50:684-697.

Wang, Y., K. Noguchi, and I. Terashima. 2008. Photosynthesis-dependent and -independent re- sponses of stomata to blue, red and green monochromatic light: Differences between the normally oriented and inverted leaves of sunflower. Plant Cell Physiol. 52:479-489.

Yanagi, T. and K. Okamoto. 1996. Effects of photosynthetic flux densities of blue and red lights by super-bright light emitting diodes on net photosynthetic rate of strawberry leaves. Hort. Res. 65:328-329. (In Japanese).

Yeh, N. and J.P. Chung. 2009. High-brightness LEDs: Energy efficient lighting sources and their potential in indoor plant cultivation. Renew. Sustain. Energy Rev. 13:2175-2180. 